\title{
Genetic Influences on Female Infidelity and Number of Sexual Partners in Humans: A Linkage and Association Study of the Role of the Vasopressin Receptor Gene (AVPR1A)
}

\author{
Lynn F. Cherkas, Elizabeth C. Oelsner, Y. T. Mak, Anna Valdes, and Tim D. Spector \\ Twin Research \& Genetic Epidemiology Unit, St Thomas' Hospital, London, United Kingdom
}

\begin{abstract}
In humans, in contrast to animals, the genetic influences on infidelity are unclear. We report here a large study of over 1600 unselected United Kingdom female twin pairs who confidentially reported previous episodes of infidelity and total lifetime number of sexual partners, as well as attitudes towards infidelity. Our findings demonstrate that infidelity and number of sexual partners are both under moderate genetic influence $(41 \%$ and $38 \%$ heritable, respectively) and the genetic correlation between these two traits is strong $(47 \%)$. Conversely, attitudes towards infidelity are driven by shared and unique environmental, but not genetic, influences. A genome-wide linkage scan identified three suggestive but nonsignificant linkage areas associated with infidelity and number of sexual partners on chromosomes 3, 7 and 20 with a maximum LOD score of 2.46. We were unsuccessful in associating infidelity or number of sexual partners with a locus implicated in other mammals' sexual behavior, the vasopressin receptor gene. Nonetheless, our findings on the heritabil-ity of sexual infidelity and number of sexual partners provide support for certain evolutionary theories of human sexual behavior, as well as justifying further genetic and molecular research in this domain.
\end{abstract}

Much remains unknown regarding the aetiology of human sexual infidelity and number of sexual partners, even though these behaviors continue to exert strong influence over many psychological and social processes (e.g., sexual jealousy, pair-bonding).

While estimates have ranged widely depending on population and selection criteria, numerous studies have indicated that over $18 \%$ of women in most western cultures have been unfaithful to a steady partner or husband (Buss, 2000; Kinsey et al., 1953). According to the Natsal 2000 (Johnson et al., 2001), 9\% of British women aged 16 to 44 had been involved in concurrent sexual partnerships in the previous year alone. Among
British families, the 'nonpaternity rate' - the rate at which children in families are biologically unrelated to the presumed 'father' - has been estimated at $1 \%$ to $1.35 \%$, while studies of other groups have generated nonpaternity estimates ranging from less than $1 \%$ to as much as $30 \%$ depending on the sample community (Cerda-Flores et al., 1999; Sasse et al., 1994). Such variability in results suggests that cultural and social factors can exert major influence on the prevalence of unfaithful and promiscuous behavior among women. However, other studies show that the effect of culture on sexual behavior is limited. For example, a recent survey of over 16,000 people from 10 world regions found universal differences between male and female preferences for number of short-term partners (Schmitt et al., 2003).

As sexual behavior is a fitness trait, there is controversy about whether or not one would expect to find genetic variation in humans. Most discussion is theoretical but suggests that heritabilities should be zero (Merila \& Sheldon, 1999). However, studies in human twins have clearly shown fitness traits (age at menarche, fertility, and age at reproduction) to be both heritable (Kohler et al., 1999) and related to reproductive fitness (Kirk et al., 2001).

Despite limited information on the basis of sexual behavior in human subjects, there is already substantial evidence demonstrating a genetic basis for sexual behavior among other pair-bonding animals, such as birds and certain rodents (Blomqvist et al., 2002). Two hormones found exclusively in mammals, oxytocin and vasopressin, not only regulate salt and water excretion, but also play roles in reproductive physiology, breast-feeding, and parent-child bonding behavior in rodents. A series of studies on rodents with diverse adult sexual behaviors has shown that

Received 25 August, 2004 ; accepted 30 August, 2004.

Address for correspondence: Tim Spector, Twin Research \& Genetic Epidemiology Unit, St Thomas' Hospital, London SE1 7EH, UK. E-mail: tim.spector@kcl.ac.uk 
levels of these hormones or their receptors in the ventral pallidum or nucleus accumbens area of the brain influence sexual and pair-bonding behavior (Insel \& Young, 2001; Young et al., 1999). Experiments using gene knockouts and transgenics have confirmed that differences in the promotor regions of the genes for these hormones and their receptors are important in behavioral phenotypes (Bielsky et al., 2003). In particular, Argenine Vasopressin (AVP) has been shown to affect a range of social behaviors in rodents - including affiliation and attachment - via the main Argenine Vasopressin $1 \mathrm{~A}$ receptor $(A V P R 1 A)$ in the brain. A recent study substantially increased monogamous behavior in the socially promiscuous meadow vole by using viral vector $V 1 a R$ gene transfer into the ventral forebrain (Lim et al., 2004). To date, there is little direct data on vasopressin's role in humans, although sexual stimulation and copulation increase blood levels (Gainer \& Wray, 1994; Murphy et al., 1987), and it has been studied in relation to an extreme form of social impairment, autism (Kim et al., 2002). The 1A receptor has been shown to be principally responsible for vasopressin's effects on the brain, and its distribution in humans is believed to be mainly in the lateral septum and amygdala (Young et al.,1999).

This study uses twins to explore whether sexual infidelity and number of sexual partners are under genetic influence in human females, thus testing the likelihood of certain evolutionary theories on pairbonding behavior. It also attempts to identify genetic linkage for these psychosocial traits, and tests for association with the AVP receptor gene that is implicated in rodent sexual behavior.

\section{Methods \\ Subjects}

Subjects for this study were monozygotic (MZ) and dizygotic (DZ) twins enlisted with the St Thomas' UK Adult Twin Registry (TwinsUK; Spector \& MacGregor, 2002). This twin population has been involved in a wide range of studies on common traits and diseases (e.g., de Lange et al., 2001; Drayna et al., 2001; Hammond et al., 2000), and has been shown to be comparable to the general population for a broad variety of medical and behavioral traits (Andrew et al., 2002; Spector \& MacGregor, 2002). After obtaining approval from the St Thomas' Hospital ethics committee, a postal self-completion questionnaire was sent to 3654 pairs of female twins aged between 19 and 83 . The approved questionnaire asked a range of questions relating to sexual attitudes and behavior. Twins were assured their responses were completely confidential, and no names or addresses were included on the questionnaire. The twins were also unaware of any specific hypotheses. Zygosity was established for all subjects with greater than $95 \%$ accuracy by using standardised questions
(Sarna et al., 1978), and it was confirmed in 54\% of the pairs by multiplex DNA fingerprinting.

\section{Classification}

Infidelity was classified as a dichotomous trait on the basis of a subject's response to the question 'Whilst married or living with a partner in a sexual relationship, have you ever had sex with someone other than your husband or partner?' Subjects were also asked with how many different people altogether they had had sexual intercourse (including both male and female partners), resulting in a continuous variable. Attitudes towards infidelity were measured with the question, "What is your general opinion of a married person having sexual relations with someone other than his/her partner?' Responses ranged from 1 (always wrong) to 5 (not at all wrong). However, because the distribution of the trait was clearly bimodal (with few respondents in categories 3, 4 or 5 ), this trait was subsequently dichotomized into those who considered infidelity to be always wrong (1), and those who did not hold this view (2-5). Twins were also asked whether they had ever been divorced or permanently separated, generating a dichotomous variable to be used as a confounder in the analyses.

\section{Statistical Analysis of Twin Data and Genetic Modeling}

An individual's phenotype is the result of the effects of both genotype and environment. To study the sources of individual differences (i.e., the variance) in a phenotype, genetically related subjects, such as twins or families, are required. The genetic relationships between twins are well-known: MZ twin pairs share all of their genes, and DZ twin pairs share, on average, $50 \%$ of their segregating genes. Assuming that both types of twins share equally similar family environments, one can assert that any greater similarity between $\mathrm{MZ}$ twins than between $\mathrm{DZ}$ twins is due to genetic influences.

Evidence for a genetic contribution to a trait can be obtained from estimating the casewise concordance for MZ and DZ twins. Casewise concordance is the probability that a twin expresses a trait given that the co-twin is affected. It is calculated from the formula $2 c /(2 c+d)$, where $c$ is the number of concordant cases, and $d$ the number of discordant cases (MacGregor, 2000). Higher concordances in MZ compared with DZ twins indicate a genetic effect.

When data suggest a genetic influence, quantitative genetic model fitting can determine the extent to which a trait is under genetic or environmental influence. Model fitting is based on comparison of the covariance (or correlation) of a trait between $\mathrm{MZ}$ and DZ twins (Neale \& Cardon, 1992). It allows separation of the observed phenotypic variance into additive genetic effects (A), dominant genetic effects (D), environmental effects shared by both twins (C), and environmental effects unique to each twin (E). A heritability estimate can be generated, defined as the 
proportion of total variation that can be explained by genetic variance (i.e., $[\mathrm{A}+\mathrm{D}] /[\mathrm{A}+\mathrm{D}+\mathrm{C}+\mathrm{E}])$. The significance of genetic and environmental factors as components of the observed variance is assessed by removing each sequentially from the full model and testing the deterioration in fit of the various submodels by hierarchic chi-squared tests. This procedure leads to submodels that explain the pattern of observed variances and covariances using as few parameters as possible. Unique environment (E) is never removed from the model, since it includes measurement error.

It is important to note that for dichotomous traits such as infidelity and attitudes towards infidelity, the maximum likelihood modeling method is used. This assumes that variation in the underlying liability of the dichotomous trait is normally distributed (Neale \& Cardon, 1992). The correlation in liability among twins is estimated from the frequencies of concordant and discordant pairs using a multifactorial liability threshold model (Falconer, 1989).

When traits are phenotypically correlated and each is significantly heritable, a multivariate genetic analysis is informative to assess the degree of genetic correlation between the traits. Multivariate model fitting enables all the information in the phenotypic correlation (and associated asymptotic covariance matrices) of the traits for both $\mathrm{MZ}$ and DZ twin pairs to be analyzed simultaneously. Three multivariate models were tested: the Cholesky decomposition, independent pathway and common pathway models. While all these models decompose the variance into three components of variation (A, C and $\mathrm{E}$ ), each represents different ways in which genes and environment may affect the observed correlations between the traits (see Neale \& Cardon, 1992, for a full description of each model). Data handling and preliminary analyses were carried out with Stata software (StataCorp, 2003), while all genetic modeling was carried out with Mx software (Neale, 1997; http:/(www.vcu.edu/mx).

\section{Linkage and Exploratory Genetic Analysis With AVPR1A}

Genome scans were performed using DNA previously extracted from venous blood samples of 515 of the $742 \mathrm{DZ}$ twin pairs who had provided infidelity data (the remaining $227 \mathrm{DZ}$ twin pairs did not have genotype data available for analysis). Scans involved using standard fluorescence-based genotyping methodologies for the analysis of 737 highly polymorphic microsatellite markers from the ABI Prism linkage mapping set (Applied Biosystems) and Genethon Genetic Linkage Map, as described previously (Wilson et al., 2003).

Multipoint genome-wide linkage analyses were then performed using an approximate $<10 \mathrm{cM}$ map and 737 markers from the ABI marker set, detailed in Wilson et al. (2003). Linkage is a way of assessing whether certain chromosomal regions (QTLs) are more likely to be shared by siblings who exhibit the same trait than would be due to chance. These areas are then likely to harbor genes that influence the trait. Infidelity and log-transformed number of sexual partners data from the $515 \mathrm{DZ}$ pairs were analyzed using variance components methods, and optimal Haseman and Elston regression methods were implemented using a Generalised Linear Model (Sham \& Purcell, 2001). The basic approach in this analysis is to regress the square of the sib-pair phenotypic difference on genetic marker identity by descent (IBD) status using GeneHunter. This method was implemented in the Stata statistical package.

In addition to the linkage analysis, association with the AVPR1A gene was tested among a subgroup of 149 DZ pairs discordant for reported fidelity status, which was believed to be the most informative. The human AVPR1A gene has been cloned and mapped to the chromosome 12q14-q15 region. This gene has only two exons spanning $6.6 \mathrm{~kb}$ on chromosome $12 \mathrm{q} 14.2$, and it codes for the 418 amino acids of AVP. A single tandem repeat (STR) was genotyped using primers (as described in Kim et al., 2002). This STR is the complex promoter $(\mathrm{CT})_{4} \mathrm{TT}(\mathrm{CT})_{8}(\mathrm{GT})_{24}$ STR $3.6 \mathrm{~kb} 5$ ' to exon 1 of the AVPR1A gene (GeneBank accession number AF208541). For this STR, 16 alleles were identified, and observed heterozygosity was $88.2 \%$ (Kim et al., 2002). Microsatellite marker-based genotyping was undertaken using standard ABI Prism ${ }^{\mathrm{TM}}$ fluorescence-based genotyping methods. Allele frequencies (proportion of chromosomes carrying a given allele) were compared using a standard chi-square. The average number of partners for each genotype was compared by analysis of variance including infidelity as a covariate. Where genotypes for both twins were available, IBD probabilities for each pair were assigned using GeneHunter. To evaluate the significance of linkage with number of partners, a weighted-likelihood approach variance-covariance model (the AE model) was used (Sham \& Purcell, 2001). Using the $\log$ transformation of the number of partners, the significance of linkage was assessed both by itself and including infidelity as a covariate. Computations were carried out using Mx Gui Version 1.4.06 (Neale \& Cardon, 1992).

\section{$\overline{\text { Results }}$}

The sexual attitudes and behavior questionnaire was returned by over 1600 complete pairs (approximately $46 \%$ complete pairs responding), comprising over 800 pairs of both MZ and DZ twins. Details of the sample are compared by zygosity in Table 1 . The MZ and DZ twin groups were well matched for rates of reported infidelity $(21 \%$ and $23 \%$ respectively), divorce $(25 \%$ and $24 \%$ respectively), number of sexual partners (means of between 4 and 5) and age (50.5 and 51.5 years respectively). The sample of respondents did not appear to be biased towards younger subjects: the average age of all respondents was 51 years, compared with an average age of 50 years for all the twins to 
Table 1

Details of Twins Studied by Zygosity

\begin{tabular}{lllc}
\hline & $\begin{array}{c}\text { Monozygotic } \\
\text { twins }\end{array}$ & $\begin{array}{c}\text { Dizygotic } \\
\text { twins }\end{array}$ & $p$ value* \\
\hline Characteristics of sample & $(n=825$ pairs $)$ & $(n=872$ pairs $)$ & \\
Mean age (years) & $50.51(19-83)^{*}$ & $51.45(19-83)^{*}$ & .13 \\
Ever unfaithful & $21 \%$ & $23 \%$ & .3 \\
Ever divorced & $25 \%$ & $24 \%$ & .65 \\
Mean lifetime number & & & .81 \\
$\quad$ of partners & $4.67(0-68)^{*}$ & $4.60(0-99)^{*}$ &.
\end{tabular}

Note: ${ }^{*} p$ values corrected for the relatedness of twins.

whom the questionnaire was sent. Ninety-eight per cent of the sample was heterosexual.

Not surprisingly, the average number of sexual partners was significantly higher among respondents who had been unfaithful compared with those who had remained faithful $(7.73$ vs. $3.78, p<.001)$. The phenotypic correlation between these traits was $.36(p<.001)$. There was a significant effect of age on number of sexual partners, with younger women more likely to have had a greater number than older women $(p<.01)$. Age was also significantly related to infidelity, with prevalence highest in middle-aged subjects (40-60 years).

For infidelity, casewise concordance rates were significantly higher in MZ than DZ twins (46\% vs. $32 \%, p<.001$ ), as shown in Table 2 . The resultant risk ratio of 1.46 for infidelity suggests that $\mathrm{MZ}$ cotwins are approximately one-and-a-half times more likely to be unfaithful if their co-twin has been unfaithful as compared with DZ co-twins. The results of genetic modeling analyses on the infidelity data are shown in Table 3. Model fitting revealed that the effects of the shared environment (C) and dominant genetic effects (D) could be dropped from the model without significant loss of fit. However, additive genetic effects $(\mathrm{A})$ could not be eliminated $(p<.001)$. This finding suggests that variance in liability to infidelity in this population is best explained by the
Table 2

Casewise Concordance Rates for Infidelity in MZ and DZ Twins

\begin{tabular}{ccccc}
\hline Zygosity & Total & $\begin{array}{c}\text { Discordant } \\
\text { pairs (+/-) }\end{array}$ & $\begin{array}{c}\text { Concordant } \\
\text { pairs (+/-) }\end{array}$ & $\begin{array}{c}\text { Casewise } \\
\text { concordance (95\% CI) }\end{array}$ \\
\hline MZ & 724 & 167 & 71 & $46(39-53) \%$ \\
DZ & 742 & 234 & 54 & $32(25-38) \%$ \\
\hline
\end{tabular}

Note: Total number of pairs may not equal the sum of concordant and discordant twins due to one or both in a twin pair failing to respond to all questions.

effects of additive genetic factors and unique environmental factors, an AE model. Estimates from this model resulted in a heritability for infidelity of $50 \%$ (95\% confidence interval, 39\% to 60\%). Adjusting the best fitting AE model for potential confounders such as divorce, number of sexual partners, and age slightly reduced the proportion of variance accounted for by unique genetic factors, yielding a final heritability estimate of $41 \%$.

Since the data relating to number of sexual partners were highly skewed and deviated significantly from a normal distribution, the data were log transformed using lnskew0 to create a new variable equal to $\ln (+/-$ oldvar $^{-\mathrm{k}}$ ), choosing $\mathrm{k}$ and the sign of the expression so that the skewness of the new variable is zero. Model fitting to the log-transformed number of sexual partners data (Table 3) suggests that an ACE model best explains the data, implying a role for both genes and shared environment. In this model, additive genetic effects contribute $41 \%$ to the variation in number of sexual partners, whereas shared environmental effects are much less important (13\%). Adjusting this model for divorce, infidelity and age resulted in a virtually unchanged genetic contribution of $38 \%$.

Multivariate model fitting to infidelity and number of sexual partners (log transformed) confirmed that a Cholesky model containing parameters for additive genetic factors and the unique environment, but without shared environmental factors, provided the best explanation of the observed correlation between the two variables. The resulting genetic correlation between the

\section{Table 3}

Genetic Modeling

\begin{tabular}{|c|c|c|c|c|}
\hline Model & $\mathrm{A}(95 \% \mathrm{CI})$ & $\mathrm{C} / \mathrm{D}(95 \% \mathrm{CI})$ & Chi-square $(d f)$ & $p$-value \\
\hline \multicolumn{5}{|c|}{ Infidelity } \\
\hline $\mathrm{ACE}$ & $0.50(0.27-0.60)$ & $0.00(0.00-0.18)$ & $6.64(3)$ & .08 \\
\hline CE & - & $0.36(0.27-0.45)$ & $19.32(4)$ & .00 \\
\hline AE & $0.50(0.39-0.60)$ & - & $6.64(4)$ & .16 \\
\hline ADE & $0.28(0.00-0.59)$ & $0.24(0.00-0.62)$ & $5.91(3)$ & .12 \\
\hline \multicolumn{5}{|c|}{ Number of sexual partners } \\
\hline ACE & $0.41(0.25-0.56)$ & $0.13(0.00-0.26)$ & $0.85(3)$ & .84 \\
\hline CE & - & $0.43(0.38-0.47)$ & $27.07(4)$ & .00 \\
\hline $\mathrm{AE}$ & $0.55(0.50-0.59)$ & - & $4.20(4)$ & .38 \\
\hline ADE & $0.55(0.42-0.59)$ & $0.00(0.00-0.12)$ & $4.20(3)$ & .24 \\
\hline
\end{tabular}

Note: $A$ = Additive genetic effects; $D=$ Dominant genetic effects; $C=$ Common environmental effects; $E=$ Unique environmental effects. Bold type indicates best-fitting model. 


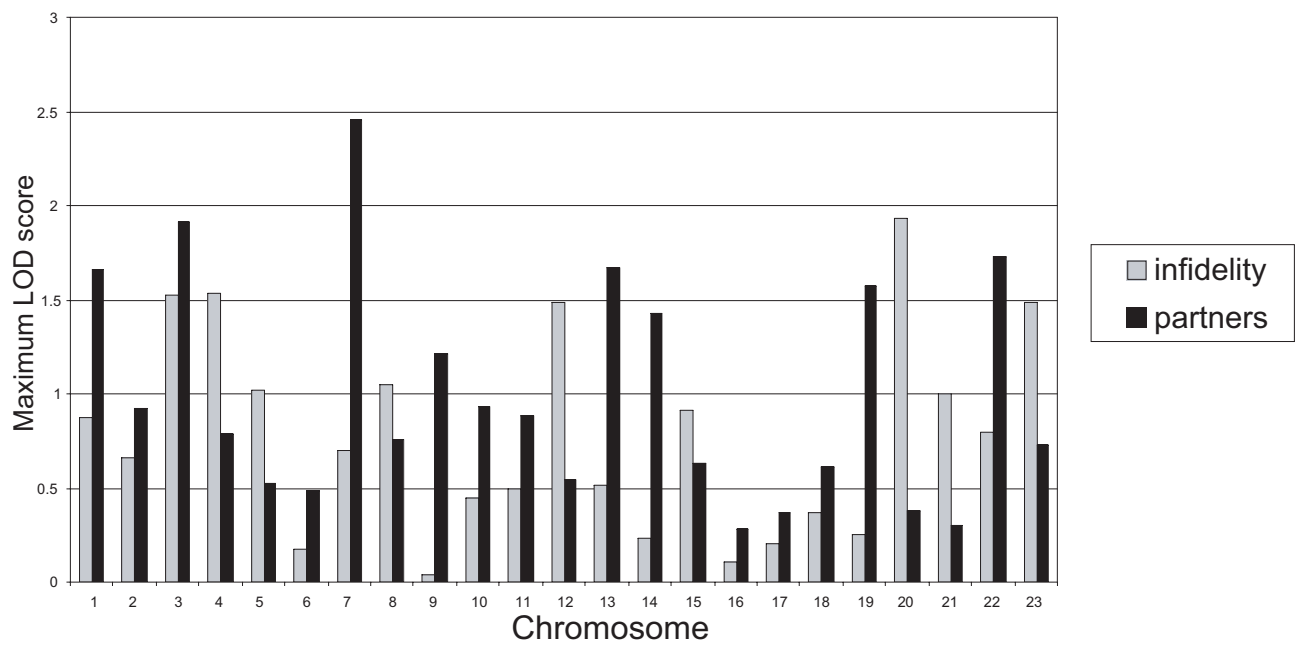

Figure 1

Linkage analysis for infidelity and number of sexual partners.

two traits was .47 , so nearly half the genes impacting on infidelity also affect number of sexual partners. The correlation of the unique environment between the two variables was .48. (The Cholesky model implies a first common genetic factor [A1] that loads on both variables and a second genetic factor [A2] that loads only on the second factor. The unique environmental factors [E1 and E2] load on the two variables in the same way.)

Women participating in the survey were also asked to indicate how strongly they approved or disapproved in principle of infidelity by either sex. Two in five women $(41 \%)$ considered it to be 'always wrong'. We found this belief to be subject solely to environmental effects, with no significant role for genetic influences. Just under one third of the variation $(30 \%)$ was attributable to the effects of the shared environment - which could include society, culture or religion - with the remaining $70 \%$ due to unique environment. It is interesting to note that believing infidelity was 'always wrong' prevailed even in some $(17 \%)$ of those women who reported having been unfaithful, highlighting the distinction between attitudes and behaviors.

Having shown both infidelity and number of sexual partners to be significantly heritable, we performed a genome-wide linkage scan. Figure 1 shows the maximum LOD score for infidelity and number of

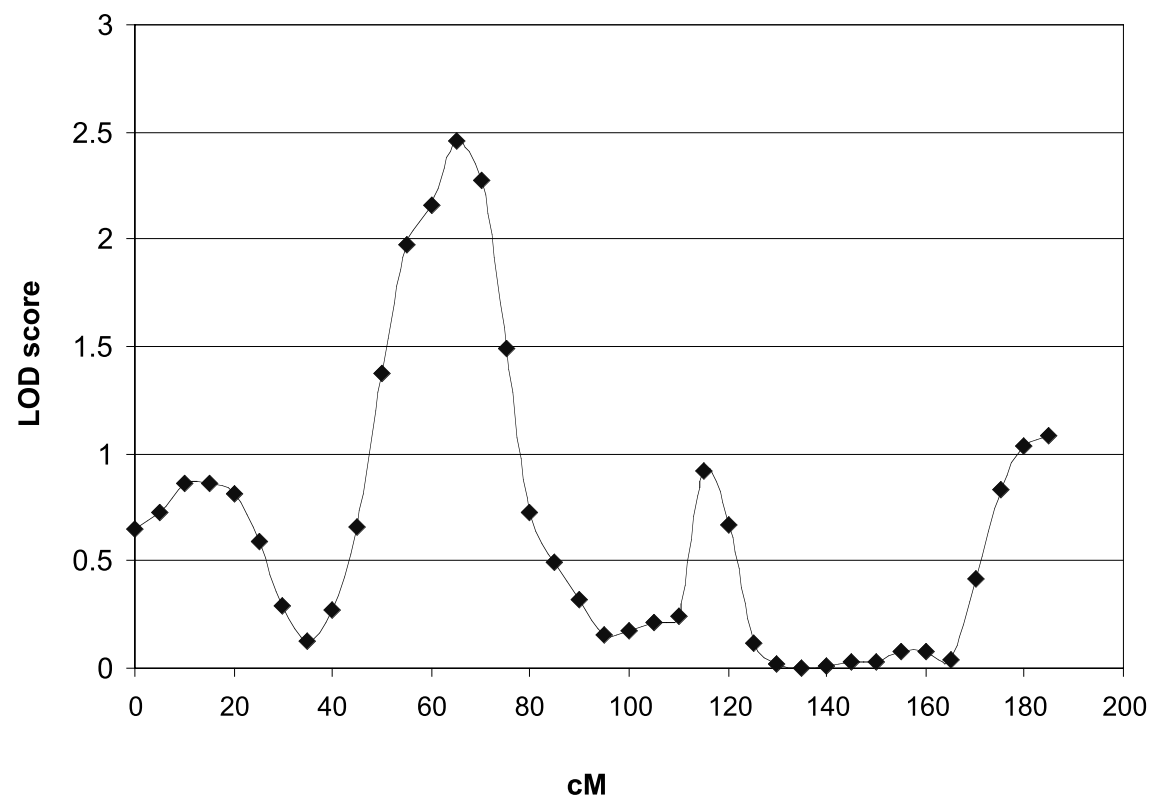

\section{Figure 2}

Linkage map for number of sexual partners on chromosome 7. 
sexual partners at each of the 23 chromosomes. Multipoint analysis showed the overall maximum linkage was for the (unadjusted) number of sexual partners (LOD 2.46) to chromosome 7 with the peak at $65 \mathrm{cM}$ (Figure 2). The maximum linkage for infidelity (LOD 1.93) was to chromosome 20 (peak at $100 \mathrm{cM}$ ) and both number of sexual partners and infidelity had suggestive linkages to areas on chromosome 3 (1.92 and 1.52 respectively), but the peaks did not overlap $(80 \mathrm{cM}$ and $210 \mathrm{cM}$ respectively). No significant association was found between the AVPR1A gene and either infidelity or number of sexual partners.

\section{$\overline{\text { Discussion }}$}

\section{Summary}

This twin study indicates that among women, $41 \%$ of variation in infidelity and $38 \%$ of variation in number of sexual partners is explained by underlying genetic variation, with little or no role for the shared environment. For infidelity, shared environmental influences were shown to have no significant effect; for number of sexual partners, they explained only $13 \%$ of variation. In contrast, genes did not seem to significantly affect attitudes towards infidelity. Whether subjects considered infidelity to be 'always wrong' was partly explained by environmental influences shared among twins, such as parents, peers and upbringing, yet $70 \%$ was due to unique environmental influences and random error. The heritability findings seen here are in a similar range $35 \%$ to $60 \%$ ) to other behavioral and complex traits reported elsewhere such as migraine, blood pressure, anxiety and depression, menarche, and age at menopause (MacGregor et al., 2000).

Despite demonstrating approximately $40 \%$ heritability for both infidelity and number of sexual partners, no conclusive linkages were found for either behavioral trait. Due to multiple testing (4 genome scans), a LOD score of 2.8 was required to confirm conventional guidelines for significant linkage. All LOD scores generated in this study fell short of this criterion (Lander \& Kruglyiak, 1995). The three QTL peaks identified on chromosomes 3, 7 and 20 may represent genes of small effect that could be confirmed by a larger study, or they may still be false positives as the power of the study to detect individual QTLs contributing less than $25 \%$ was low. On a first screen, none of these regions harboured the oxytocin or vasopressin candidate genes or any obvious alternative candidates. In addition, the association analysis failed to support the hypothesis that a gene implicated in rodent sexual behavior $(A V P R 1 A)$ could explain the observed variation in human sexual behavior.

\section{Support for Evolutionary Theory}

In general, the fact that psychosocial traits such as number of sexual partners and infidelity appear to behave as other common complex genetic traits in humans, in that they have a heritable component, lends support to evolutionary psychologists' theories on the origins of human behavior (Bailey et al., 2000). If female infidelity and number of sexual partners are under considerable genetic influence as this study demonstrates, the logical conclusion is that these behaviors persist because they have been evolutionarily advantageous for women. Along with the findings of Kirk et al. (2001), the fact that a fitness trait is still heritable today suggests that recent selective pressures may still be operating.

The findings add to a growing body of evidence supporting pluralistic theories of human female mating (discussed in Schmitt et al., 2003). For a woman, the advantages of securing a long-term mating partner are clear: given the amount of parental investment required to bear and raise children, a woman will benefit from having a male who protects and supports both her and her offspring throughout gestation and early development. Once a woman has established a long-term partner with whom she is socially monogamous, sexual monogamy is not necessarily advantageous to her unless her longterm partner is the most genetically fit male available - an unlikely position - or unless the risks involved with infidelity outweigh the benefits.

Thus, from an evolutionary perspective, a woman's optimal short-term strategy would be to clandestinely pursue extra-pair matings with genetically better or more diverse males, if the risk was minimal. To this point, studies of certain animals and human tribes have shown that when females choose multiple fathers, they are on average more fertile and have more viable offspring than when they are sexually monogamous (Hrdy, 2000). Recent DNA-based paternity studies of certain socially monogamous shorebirds further support the hypothesis that the pursuit of genetic variability is a key driver for female infidelity: female shorebirds were more likely to be unfaithful when their own DNA were more closely related to their original partner's than to the new 'more foreign' male (Blomqvist et al., 2002). There are many alternative theoretical 'benefits' of infidelity including improving social status and resources, a prelude to changing a mate permanently, providing a back-up mate for protection, making a partner jealous and improving self-esteem (Fisher, 1992).

Although this is the first study among women to demonstrate a genetic basis for infidelity, other studies have already shown aspects of sociosexuality and number of partners to be heritable (Bailey et al., 2000). Others have studied a range of subconscious behaviors linked with mating strategies (Buss, 2000). According to one study, women tend to fantasize about infidelity, have more extramarital sex, and show less interest in their regular partners in the middle of their cycle prior to ovulation, when they are at their most fertile (Gangestad et al., 2002). Work in the UK has shown that human females generally have affairs with men of higher status than their husbands 
(Baker \& Bellis, 1995), perhaps illustrating an effort to mate with a genetically superior partner.

Of course, in primarily socially monogamous species, excessive female infidelity or increasing number of sexual partners could lead to detection and subsequently the abandonment, ostracism or murder of both offspring and mother. Thus, having a balance of chaste, promiscuous, faithful and unfaithful females in the human population may well have been a key component of the species' success, as supported by exponents of game theory (Dawkins, 1989). Our findings support the hypothesis that underlying genetic variance may serve to maintain such an advantageous phenotypic variance.

\section{Limitations and Implications for Future Research}

As in any twin study, the key issues to address are whether our method effectively tests for the traits of interest, whether the twin assumptions hold for the traits of interest, and whether our results are generalizable to singletons.

As with any survey of 'embarrassing' or socially unacceptable information, there is likely to be some degree of misreporting. A recent study has shown that women underreported embarrassing information when their data were not entirely confidential, and that honesty could be optimized by fake polygraph testing (Alexander \& Fisher, 2003). To address this concern, the questionnaires used in this study were completed anonymously, with no names or identifying personal details attached besides a twin pair number. Thus, although they may have been inferior to the more stringent 'lie detection' approach, our conditions were considerably more likely to produce accurate responses than nonanonymous surveys (Alexander \& Fisher, 2003). The results also incorporate some recall bias, since subjects were asked to report their total lifetime number of sexual partners. For instance, the data suggest that some respondents with over 30 lifetime partners 'rounded off' their numbers. The effects of underreporting or random misreporting would be the misclassification of individuals, which would likely result in both an underestimation of heritability and less power to find genes.

The findings are dependent to some degree on the equal environments assumption, that is, the assumption that $M Z$ and $D Z$ twin pairs share their environment to the same degree and that a greater phenotypic similarity among $\mathrm{MZ}$ than $\mathrm{DZ}$ twins results from their two-fold greater genetic similarity. If this assumption is not accurate, heritability may be overestimated (Hopper, 2000). Still, there is abundant research to suggest that the assumption is valid for behavioral and psychological phenotypes such as the ones we have analyzed (Kyvik, 2000). In order to test specifically for whether the equal environments assumption is appropriate in the context of this study, it is important to compare the response rates and the prevalence of traits across MZs and DZs. The groups were well matched for response rates, age, and reported infidelity and number of sexual partners. Also, no differences were found in absolute rates of divorce between MZ and DZ twins, which suggest there are no important biases between the groups for success in maintaining long-term relationships. If one accepts that DZs would be no more likely than MZs to misreport infidelity and number of sexual partners, these results support the conclusion that the twin assumption is acceptable for these traits. Furthermore, the findings are consistent with other twin studies on related phenotypes. One twin study looking at a number of scaled sociosexual behaviors found a similar heritability for number of sexual partners in male and female twins (Bailey et al., 2000); another study showed divorce to be approximately $50 \%$ heritable among women (Jockin et al., 1996).

We believe our results to be generalizable to singletons based on the nature and size of our sample, as well as the reasonableness of our results. A population was used that has already been shown to be representative of the overall British population for a wide variety of medical, psychological and social traits (Andrew et al., 2002). We achieved an approximately $46 \%$ pair-wise response rate, which is comparable to our typical response rate of $50 \%$ to $60 \%$ for medically oriented twin surveys. The overall response rate was approximately $50 \%$, which does not rule out the potential for some respondent bias. In other words, it is possible that the respondents may have differed from nonrespondents in terms of unfaithful or promiscuous behavior. Still, average age did not differ significantly among respondents and nonrespondents, indicating that the sample was not biased in this respect. Moreover, the methods produced reported rates of infidelity that are similar to other surveys (Buss, 2000), suggesting the sample was not significantly distorted from the normal population and thus the results can be generalized.

By demonstrating the heritability of female infidelity and number of sexual partners in humans, this study justifies additional genetic and molecular research on human sexual behavior. While the study failed to prove genetic linkage with any sex or related hormones, or association with the AVPR1A gene, conclusive results may be obtained by using a larger sample. Resequencing of the gene to find other variants may also be important. It is also possible that genes influencing risk-taking or sensation-seeking behavior are also in part related to fidelity traits, as may be genes that seek powerful controlling partners (Koopmans et al., 1995; Miles et al., 2001). In subsequent linkage and association studies, a number of specific genes should be considered as targets. For although human sexual behavior is clearly complex, the genes for certain hormones and their receptors are likely to play a role. In addition to vasopressin and its receptors, one of which was used in the exploratory genetic analysis, oxytocin is also suspected to play a role in sexual behavior. It differs from vasopressin by 
only a few amino acids, and has yet to be well characterized in humans. Dopamine has also been implicated in many human behavioral traits, and studies in other animals suggest that the D2 receptor deserves further study (Insel, 2003; Gingrich et al., 2000). It has been suggested that oxytocin and AVP enhance the dopaminergic 'reward' pathways involving the hypothalamus, and regulate our levels of social bonding and attachment (Aragona et al., 2003; Insel et al., 2001). Lastly, genes for the primary female sex hormone, oestrogen, and its receptors, should of course be included in the list of candidates for future linkage and association studies.

\section{Acknowledgments}

We would like to thank Ann Johnson for help with the questions. TwinsUK receives funding from the Wellcome Trust and the CDRF.

\section{References}

Alexander, M. G., \& Fisher, T. D. (2003). Truth and consequences: Using the bogus pipeline to examine sex differences in self-reported sexuality. Journal of Sex Research, 40, 27-35.

Andrew, T., Johnson, W., Krueger, R. F., Bouchard, T. J., Jr., \& McGue, M. (2002). The personalities of twins: Just ordinary folks. Twin Research, 5, 125-131.

Aragona, B. J., Liu, Y., Curtis, J. T., Stephan, F. K., \& Wang, Z. (2003). A critical role for nucleus accumbens dopamine in partner preference formation in male prairie voles. Journal of Neuroscience, 23, 3483-3490.

Bailey, J. M., Kirk, K. M., Zhu, G., Dunne, M. P., \& Martin, N. G. (2000). Do individual differences in sociosexuality represent genetic or environmentally contingent strategies? Evidence from the Australian twin registry. Journal of Personality and Social Psychology, 78, 537-545.

Baker, R. R., \& Bellis, M. A. (1995). Human sperm competition: Copulation, masturbation, and infidelity. London: Chapman and Hall.

Bielsky, I. F., Hu, S. B., Szegda, K. L., Westphal, H., \& Young, L. J. (2003). Profound impairment in social recognition and reduction in anxiety-like behavior in Vasopressin V1a receptor knockout mice. Neuropsychopharmacology, 29, 483-493.

Blomqvist, D., Andersson, M., Kupper, C., Cuthill, I. C., Kis, J., Lanctot, R. B., Sandercock, B. K., Szekely, T., Wallander, J., \& Kempenaers, B. (2002). Genetic similarity between mates and extra-pair parentage in three species of shorebirds. Nature, 419, 613-615.

Buss, D. M. (2000). Desires in human mating. Annals of the New York Academy of Sciences, 907, 39-49.

Cerda-Flores, R. M., Barton, S. A., Marty-Gonzalez, L. F., Rivas, F., \& Chakraborty, R. (1999). Estimation of nonpaternity in the Mexican population of Nuevo Leon: A validation study with blood group markers.
American Journal of Physical Anthropology, 109, 281-293.

Dawkins, R. (1989). The selfish gene: New edition. Oxford, UK: Oxford University Press.

de Lange, M., Snieder, H., Ariens, R. A. S., Spector, T. D., \& Grant, P. J. (2001). The genetics of haemostasis: A twin study. The Lancet, 357, 101-105.

Drayna, D., Manichaikul, M., de Lange, M., Snieder, H., \& Spector, T. D. (2001). Genetic correlates of musical pitch recognition in humans. Science, 291, 1969-1972.

Falconer, D. S. (1989). Introduction to Quantitative Genetics (3rd ed.). Essex, UK: Longman Scientific \& Technical.

Fisher, H. E. (1992) The anatomy of love. New York: Ballantine.

Gainer, H., \& Wray, S. (1994). Cellular and molecular biology of oxytocin and vasopressin. In E. Knobil \& J. Neill (Eds.), The physiology of reproduction (2nd ed., pp. 1099-130). New York: Raven Press.

Gangestad, S. W., Thornhill, R., \& Garver, C. E. (2002). Changes in women's sexual interests and their partners' mate-retention tactics across the menstrual cycle: Evidence for shifting conflicts of interest. Proceedings of the Royal Society of London B, 269, 975-982.

Gingrich, B., Liu, Y., Cascio, C., Wang, Z., \& Insel, T. R. (2000). Dopamine D2 receptors in the nucleus accumbens are important for social attachment in female prairie voles (Microtus ochrogaster). Behavioral Neuroscience, 114, 173-183.

Hammond, C. J., Snieder, H., Spector, T. D., \& Gilbert, C. E. (2000). Genetic and environmental factors in age-related nuclear cataracts in monozygotic and dizygotic twins. New England Journal of Medicine, 342, 1786-1790.

Hopper, J. L. (2000). Why 'common environmental effects' are so uncommon in the literature. In T. D. Spector, H. Snieder, \& A. J. MacGregor (Eds.), Advances in twin and sib-pair analysis (pp. 151-166). London, UK: Greenwich Medical Media.

Hrdy, S. B. (2000). The optimal number of fathers: Evolution, demography, and history in the shaping of female mate preferences. Annals of the New York Academy of Sciences, 907, 75-95.

Insel, T. R. (2003). Is social attachment an addictive disorder? Physiology and Behavior, 79, 351-357.

Insel, T. R., Gingrich, B. S., \& Young, L. J. (2001). Oxytocin: Who needs it? Progress in Brain Research, 133, 59-66.

Insel, T. R., \& Young, L. J. (2001). The neurobiology of attachment. Nature Reviews Neuroscience, 2, 129-136.

Jockin, V., McGue, M., \& Lykken, D. T. (1996). Personality and divorce: A genetic analysis. Journal of Personality and Social Psychology, 71, 288-299. 
Johnson, A. M., Mercer, C. H., Erens, B., Copas, A. J., McManus, S., Wellings, K., Fenton, K. A, Korovessis, C., Macdowall, W., Nanchahal, K., Purdon, S., \& Field, J. (2001). Sexual behaviour in Britain: Partnerships, practices, and HIV risk behaviours. The Lancet, 358, 1835-1842.

Kim, S. J., Young, L. J., Gonen, D., VeenstraVanderWeele, J., Courchesne, R., Courchesne, E., Lord, C., Leventhal, B. L., Cook, E. H., Jr., \& Insel, T. R. (2002). Transmission disequilibrium testing of arginine vasopressin receptor 1A (AVPR1A) polymorphisms in autism. Molecular Psychiatry, 7, 503-507.

Kinsey, A. C., Pomeroy, W. B., \& Martin, C. E. (1953). Sexual behaviour in the human female. Philadelphia, PA: Saunders.

Kirk, K. M., Blomberg, S. P., Duffy, D. L., Heath, A. C., Owens, I. P., \& Martin, N. G. (2001). Natural selection and quantitative genetics of life-history traits in Western women: A twin study. Evolution: International Journal of Organic Evolution, 55, 423-435.

Kohler, H.-P., Rodgers , J. L., \& Christensen, K. (1999). Is fertility behavior in our genes? Findings from a Danish twin study. Population and Development Review, 25, 253-288.

Lander, E., \& Kruglyak, L. (1995). Genetic dissection of complex traits: Guidelines for interpreting and reporting linkage results. Nature Genetics,11, 241-247.

Koopmans, J. R., Boomsma, D. I., Heath, A. C., \& van Doornen, L. J. (1995). A multivariate genetic analysis of sensation seeking. Behavior Genetics, 25, 349-356.

Kyvik, K. O. (2000). Generalisability and assumptions of twin studies. In T. D. Spector, H. Snieder, \& A. J. MacGregor (Eds.), Advances in twin and sib-pair analysis (pp. 67-78). London, UK: Greenwich Medical Media.

Lim, M. M., Wang, Z., Olazabal, D. E., Ren, X., Terwilliger, E. F., \& Young, L. J. (2004). Enhanced partner preference in a promiscuous species by manipulating the expression of a single gene. Nature, 429, $754-757$.

MacGregor, A. J. (2000). Practical approaches to account for bias and confounding in twin data. In T. D. Spector, H. Snieder, \& A. J. MacGregor (Eds.), Advances in twin and sib-pair analyses (pp. 35-52). London: Greenwich Medical Media.

MacGregor, A. J., Snieder, H., Schork, N. J., \& Spector, T. D. (2000).Twins: Novel uses to study complex traits and genetic diseases. Trends in Genetics, 16, 131-134.

Merila, J., \& Sheldon, B. C. (1999). Genetic architecture of fitness and nonfitness traits: Empirical patterns and development of ideas. Heredity, 83,103-109.

Miles, D. R., van den Bree, M. B., Gupman, A. E., Newlin, D. B., Glantz, M. D., \& Pickens, R. W. (2001). A twin study on sensation seeking, risk taking behavior and marijuana use. Drug and Alcohol Dependence, 62, 57-68.

Murphy, M., Seckl, J., Burton, S., Checkley, S., \& Lightman, S. (1987). Changes in oxytocin and vasopressin secretion during sexual activity in men. Journal of Clinical Endocrinology and Metabolism, $65,738-741$.

Neale, M. C., \& Cardon, L. R. (1992). Methodology for genetic studies of twins and families. Dordrecht, the Netherlands: Kluwer Academic.

Neale, M. C. (1997). Mx: Statistical modeling (4th ed; software). Richmond, VA: Department of Psychiatry, Medical College of Virginia.

Sasse, G., Muller, H., Chakraborty, R., \& Ott, J. (1994). Estimating the frequency of nonpaternity in Switzerland. Human Heridity, 44, 337-343.

Sarna, S., Kaprio, J., Sistonen, P., \& Koskenvuo, M. (1978). Diagnosis of twin zygosity by mailed questionnaires. Human Heredity, 28, 241-254.

Schmitt, D. P., Alcalay, L., Allik, J., Ault, L., Austers, I., Bennett, K. L., Bianchi, G., Boholst, F., Cunen, M. A., Braeckman, J., Brainerd, E. G., Jr., Caral, L. G., Caron, G., Casullo, M. M., Cunningham, M., Daibo, I., De Backer, C., De Souza, E., Diaz-Loving, R., Diniz, G., Durkin, K., Echegaray, M., Eremsoy, E., Euler, H. A., Falzon, R., Fisher, M. L., Foley, D., Fry D. P., Fry, S., Ghayur, M. A., Golden, D. L., Grammer, K., Grimaldi, L., Halberstadt, J., Herrera, D., Hertel, J., Hoffmann, H., Hooper, D., Hradilekova, Z., Hudek-Kene-evi, J., Jaafer, J., Jankauskaite, M., Kabangu-Stahel, H., Kardum, I., Khoury, B., Kwon, H., Laidra, K., Laireiter, A. R., Lakerveld, D., Lampert, A., Lauri, M., Lavallee, M., Lee, S. J., Leung, L. C., Locke, K. D., Locke, V., Luksik, I., Magaisa, I., Marcinkeviciene, D., Mata, A., Mata, R., McCarthy, B., Mills, M. E., Moreira, J., Moreira, S., Moya, M., Munyae, M., Noller, P., Opre, A., Panayiotou, A., Petrovic, N., Poels, K., Popper, M., Poulimenou, M., P'yatokha, V., Raymond, M., Reips, U. D., Reneau, S. E., Rivera-Aragon, S., Rowatt, W. C., Ruch, W., Rus, V. S., Safir, M. P., Salas, S., Sambataro, F., Sandnabba, K.N., Schulmeyer, M. K., Schutz, A., Scrimali, T., Shackelford, T. K., Shaver, P. R., Sichona, F., Simonetti, F., Sinehsaw, T., Speelman, T., Spyrou, S., Sumer, H. C., Sumer, N., Supekova, M., Szlendak, T., Taylor, R., Timmermans, B., Tooke, W., Tsaousis, I., Tungaraza, F. S., Vandermassen, G., Vanhoomissen, T., Van Overwalle, F., Vanwesenbeeck, I., Vasey, P. L., Verissimo, J., Voracek, M., Wan, W. W., Wang, T. W., Weiss, P., Wijaya, A., Woertman, L., Youn, G., \& Zupaneie, A. (2003). Universal sex differences in the desire for sexual variety: Tests from 52 nations, 6 continents, and 13 islands. Journal of Personality and Social Psychology, 85, 85-104.

Sham, P. C., \& Purcell, S. (2001). Equivalence between Haseman-Elston and variance-components linkage analyses for sib pairs. American Journal of Human Genetics, 68, 1527-1532. 
Spector, T. D., \& MacGregor, A. J. (2002). The St Thomas' UK adult twin registry. Twin Research, 5, 440-443.

StataCorp. (2003). Stata Statistical Software (Release 8.0) [Computer software]. College Station, TX: StataCorporation.

Wilson, S. G., Reed, P. W., Bansal, A., Chiano, M., Lindersson, M., Langdown, M., Prince R. L., Thompson, D., Thompson, E., Bailey, M., Kleyn, P. W., Sambrook, P., Shi, M. M., \& Spector, T. D.
(2003). Comparisons of genome screens for two independent cohorts provides replication of suggestive linkage of bone mineral density to $3 \mathrm{p} 21$ and $1 \mathrm{p} 36$. American Journal of Human Genetics, 2003, 72, 144-155.

Young, L. J., Nilsen, R., Waymire, K. G., MacGregor, G. R., \& Insel, T. R. (1999). Increased affiliative response to vasopressin in mice expressing the $\mathrm{V} 1 \mathrm{a}$ receptor from a monogamous vole. Nature, 400, $766-768$. 